\author{
E-ISSN: 2469-6501 \\ VOL: 7, ISSUE: 12 \\ December/2021 \\ DOI: http://dx.doi.org/10.33642/ijbass.v7n12p2 \\ (c) (i) \\ https://creativecommons.org/licenses/by/4.0/
}

\title{
The Relationship between Self-efficacy and Emotional Intelligence (EI) among Tour Guides
}

\author{
Jennifer Chen-Hua Min \\ Professor \\ Department of International Business \\ Ming Chuan University \\ Email: jennifer_min.tw@yahoo.com.tw
}

Taiwan

\section{ABSTRACT}

Self-efficacy is a key determinant of successful performance and plays a critical role in affecting an individual's motivation and behavior. It refers to individuals' levels of confidence in their ability to execute a course of action or achieve specific performance outcomes. Emotional intelligence (EI), or the intelligent use of emotions, is being recognized as a significant factor at work, and it can be enhanced through proper EI training interventions. Therefore, this study uses self-evaluation to achieve a better understanding of how EI relates to the self-efficacy among tour guides, who significantly influence tourists' impressions of a destination. Structural equation modeling (SEM) is used to examine significant relationships between these factors. The results found all EI variables, including Self-Emotion Appraisal, Others' Emotion Appraisal, Regulation of Emotion, and Use of Emotion, are positively associated with self-efficiency. The results have practical implications, as the abilities of EI are improved through the proper interventions which in turn allow an individual to become more confident in successfully completing tasks when faced with challenging situations, resulting in an increase in one's positive mindset.

\section{Keywords: Self-efficacy, Emotional intelligence, training, tourism industry, tour guides}

\section{INTRODUCTION}

Bandura's social cognitive theory proposed in 1977 led to the development of the concept of self-efficacy, which refers to how people view their ability to carry out actions needed in certain situations. A central proposition of social cognitive theory is that self-efficacy is a key determinant of successful performance and plays a critical role in affecting an individual's motivation and behavior. In other words, how people view their ability to attain their goals has an effect on the individual cognitive and behavioral reaction. Bandura (1997) also found that high levels of self-efficacy enable people to better deal with difficult situations and tasks, feel less disturbed by them, and experience less strain and depression, leading to successful task completion. On the other hand, when people have low levels of self-efficacy they will feel less able to cope with difficult situations and tasks, will dwell more on obstacles and their own deficiencies, and as a result, will experience more strain and depression. This loss of confidence in their capabilities causes discouragement and failure. While considerable evidence of the importance of selfefficacy has been acknowledged, further to its implications for job performance or life quality, the importance of self-efficacy to people's work-related variables has been most comprehensively examined in the context of different workrelated outcomes in management and academics. These associations have been demonstrated by many studies, such as recent research by Kraut et al. (2016) and Dixon et al. (2014) among teachers.

Emotional Intelligence (EI), a term first coined by Peter Salovey and John Mayer in 1990, is described as "the ability to monitor one's own and others' feelings and emotions, to discriminate among them, and to use this information to guide one's thinking and actions" (p. 189). Furthermore, Mayer and Salovey (1997) explain EI as the ability to perceive emotions, assimilate feelings related to emotions, understand what emotions mean, and manage emotions effectively. In 1995, the concept of EI became popular in the business community and among the general public after the publication of Daniel Goleman's New York Times bestseller Emotional intelligence: Why it can matter more than IQ. The author explains that Intelligence Quotient (IQ) is considered to account for approximately $20 \%$ of the factors that determine life success, and he argues that EI can account for the remaining factors. EI can thus be considered a significant factor in success at home, at work, and in school. In the three decades since its publication, the usefulness of the EI construct has led researchers to examine its potency in various aspects of human functioning in the work environment. Numerous studies have found that EI is associated with a number of positive outcomes in the workplace and interpersonal relationships. According to these findings, individuals with high EI tend to be welladjusted, skilled at assessing different contexts, capable of using emotions to guide thoughts and actions, and adept at reflecting on their emotions to bring about personal and intellectual growth (Goleman, 1998; Wong \& Law, 2002; Min, 2014).

To date, the research has shown a clear relationship between emotions and self-efficacy. Emotions are characterized by their ability to motivate and regulate actions, as well as to facilitate the assessment and implementation of specific goals or tasks (Min, 2014; Jiang, 2014). Such regulation and control of emotions is a useful skill for all people. According to Bedwell (2002), emotions may have an effect on how people make decisions, solve problems, interact 


\author{
E-ISSN: 2469-6501 \\ VOL: 7, ISSUE: 12 \\ December/202 1 \\ DOI: http://dx.doi.org/10.33642/ijbass.v7n12p2

with others, and use creativity in work settings. The use of emotions in these areas is consistent with the behaviors related to self-efficacy. In this view, EI can be seen as a set of abilities that relate closely to motivation.

In recent decades, several studies have found that those with high EI tend to better organize thoughts and emotions during times of stress, which results in more positive outlooks and enhanced abilities to adapt to challenging situations and solve problems effectively and confidently (Min, 2014). These characteristics comprise a sense of self-efficacy, which makes it possible for people to successfully complete tasks. Numerous studies of the workplace have provided evidence that EI skills can enhance the efficacy and productivity of employees, which results in greater commitment and increased overall efficiency in the organization (Chan, 2004; Tabatabaei, Jashani, Mataji, \& Afsar, 2013)

Although evidence for the relationship between EI and workers' self-efficacy is supported, there has been no investigation of the relationship between them among tour guides, who act as intermediaries between tourists and an unfamiliar environment and significantly influence tourists' impressions of a destination. In particular, Taiwan's government has implemented policies to improve inbound tourism in recent years. Therefore, with such an important role to play in people's success, it is of interest to know how tour guides' self-efficacy is influenced by other crucial variables, such as EI. In addition, research has identified that the competencies of EI can be learned and enhanced through proper training techniques (Goleman, 1998). Once learned, the abilities of EI and self-efficacy can be improved, which in turn allows an individual to become more confident in successfully completing tasks when faced with challenging situations, resulting in an increase in one's positive mindset.

\section{LITERATURE REVIEW}

\section{Self-efficacy}

Self-efficacy refers to individuals' levels of confidence in their ability to execute a course of action or achieve specific performance outcomes (Bandura, 1997). People who have high self-efficacy will believe in their ability to perform a specific task, and this results in greater perseverance, better flexibility at coping with challenges, and an enhanced feeling of selfaccomplishment. Conversely, people with low self-efficacy will have less confidence in their ability to perform a specific task, which results in them giving up prematurely and thus failing at higher rates.

\section{Emotional Intelligence (EI)}

There are two main conceptualizations of EI: the ability-based and the trait-based (or mixed) models. The ability-based model, conceived by Salovey and Mayer, views EI as a form of pure intelligence; put simply, EI involves a person's ability to reason about emotions and to process emotional information in order to regulate behavior. This model involves three mental processes: (a) the appraisal and expression of emotions in oneself and others, (b) the regulation of emotion in oneself and others, and (c) the utilization of emotions to facilitate thought. The model further divided these processes into subcomponents. Although the ability-based model is a somewhat general view of EI, it also takes into account individual differences in mental processes and abilities (Mayer \& Geher, 1996; Mayer \& Salovey, 1993).

Goleman (1995, 1998) and Bar-On (1997) proposed the trait-based model, which views EI as a mixed form of intelligence, consisting of cognitive ability and personality aspects. Goleman expanded upon Salovey and Mayer's model by incorporating what he describes as personal and social competencies. In Goleman's model, EI consists of five variables which are categorized in two dimensions: personal competencies (self-awareness, self-regulation, and motivation) and social competencies (empathy and social skills). Bar-On (1997) built on this model, conceptualizing EI as a noncognitive ability involving five broad skill areas which people can use to more effectively deal with environmental demands and pressures: intrapersonal skills, interpersonal skills, adaptability, stress management, and general mood. However, unlike Bar-On's model, Goleman's model is more focused on how workplace success can be determined by cognitive and personality factors.

\section{EI and Self-efficacy}

Past research on the relationship between EI and selfefficacy has examined this issue in great depth. For instance, Walter et al. (2015) researched the academic self-efficacy of Israeli students who were at risk for attrition in higher. The results found that courses could effectively promote the development of EI, enhance students' sense of academic selfefficacy, and enable them to use coping strategies in a way to reduce attrition rates. Chan (2004) investigated the role of perceived EI and self-efficacy among secondary school teachers, with the finding that EI was an effective measure for predicting self-efficacy toward helping others. A study by Idrus, Alhabji, Al Musadieq, and Utami (2015) looked at tour guides' burnout from the perspectives of psychological empowerment. Their finding that self-efficacy has a significant positive effect on EI stood in contrast to previous research, though it should be noted that their study lacked a literature review.

\section{METHODOLOGY}

This study involves collecting and analyzing quantitative data to assess the relationships among selfefficacy and EI among the tour guide population. Two selfreport instruments using a 5-point Likert scale were adopted to assess the relationship between the variables. The measurements include Wong and Law's Emotional Intelligence Scale (WLEIS) (2002) and the Chinese version of the General Self-Efficacy Scale developed by Schwarzer, and Jerusalem (1995). The scale of WLEIS consists of four dimensions containing four items each, and this scale is used to assess individuals' knowledge about their emotional capacities. The dimensions included in this scale are Self-Emotion 
Appraisal (SEA), Others' Emotion Appraisal (OEA), cases consisted of 234 males (56.7\%) and 179 females Regulation of Emotion (ROE), and Use of Emotion (UOE). (43.3\%), which is an accurate reflection of the gender Therefore, the research hypotheses are: proportions of Taiwan's tour guide population (59\%: 41\%) H1: A higher level of Self-Emotion Appraisal is associated (Tourism Bureau, 2018). The majority of respondents were with a higher level of self-efficacy among tour guides. over 40 years old $(81.6 \%)$, and more than half of the H2: A higher level of Others' Emotion Appraisal is associated with a higher level of self-efficacy among tour guides. respondents $(70.7 \%)$ were university graduates $(47.9 \%$ H3: A higher level of Regulation of Emotion is associated with a higher level of self-efficacy among tour guides. undergraduate; $22.8 \%$ postgraduate). Regarding marital status, H4: A higher level of Use of Emotion is associated with a higher level of self-efficacy among tour guides.

EMPIRICAL RESULTS

A total of 500 surveys were distributed, and the language. profiles of the respondents are shown in Table 1. The usable

Table 1. Demographic Profile of Respondents

\begin{tabular}{|c|c|c|}
\hline & Frequency $(N=413)$ & $\%$ \\
\hline \multicolumn{3}{|l|}{ Gender } \\
\hline male & 234 & 56.7 \\
\hline female & 179 & 43.3 \\
\hline \multicolumn{3}{|l|}{ Age group } \\
\hline $20 \sim 29$ years & 28 & 6.8 \\
\hline $30 \sim 39$ years & 48 & 11.6 \\
\hline $40 \sim 49$ years & 99 & 24.0 \\
\hline $50 \sim 59$ years & 171 & 41.4 \\
\hline 60 years and above & 67 & 16.2 \\
\hline \multicolumn{3}{|l|}{ Education } \\
\hline vocational school & 33 & 8.0 \\
\hline college & 88 & 21.3 \\
\hline university & 198 & 47.9 \\
\hline postgraduate & 94 & 22.8 \\
\hline \multicolumn{3}{|l|}{ Marital status } \\
\hline single & 264 & 63.9 \\
\hline married & 135 & 32.7 \\
\hline divorced or windowed & 14 & 3.4 \\
\hline \multicolumn{3}{|l|}{ Language } \\
\hline Chinese & 293 & 70.7 \\
\hline English & 39 & 9.4 \\
\hline Japanese & 13 & 3.1 \\
\hline others & 14 & 3.4 \\
\hline more than one language & 55 & 13.3 \\
\hline \multicolumn{3}{|l|}{ Work experience } \\
\hline under 1 years & 71 & 17.2 \\
\hline $1-9$ years & 269 & 65.1 \\
\hline 10-19 years & 51 & 12.3 \\
\hline $20-29$ years & 13 & 3.1 \\
\hline $30-39$ years & 6 & 1.5 \\
\hline 40 years above & 3 & 0.7 \\
\hline
\end{tabular}

The collected data were analyzed using SPSS 20.0 and The Cronbach alphas, ranging from 0.818 to 0.911 , indicating SmartPLS 3.2.4 for Windows. The reliability coefficients, that internal consistency exists. In terms of intercorrelations, means, standard deviations, and the intercorrelations amongst there were significant correlations amongst all the dimensions. the various measures and the subscales are shown in Table 2. Table 2 also revealed, as expected, that tour guides' tour 
dimensions of EI were positively and significantly related to self-efficacy.

The collected data were analyzed using SPSS 20.0 and SmartPLS 3.2.4 for Windows. The reliability coefficients, means, standard deviations, and the intercorrelations amongst the various measures and the subscales are shown in Table 2. The Cronbach alphas, ranging from 0.818 to 0.911 , indicating that internal consistency exists. In terms of intercorrelations, there were significant correlations amongst all the dimensions. Table 2 also revealed, as expected, that tour guides' tour dimensions of EI were positively and significantly related to self-efficacy.

Assessment of Measurement Model and Hypotheses

\section{Testing}

The indicators of goodness of fit are comparative fit index $(\mathrm{CFI})=0.974$, normed fit index $(\mathrm{NFI})=0.960$, Non-
Normed Fit Index $($ NNFI) $=0.971$ (acceptably $\geq 0.90)$, and root mean square error of approximation (RMSEA) $=0.064$ (acceptably $\leq 0.08$ ). Based on the results, all of the model-fit indices exceeded the common acceptance levels, thus demonstrating that the hypothesized model fits the empirical data well.

The present study tested four hypotheses through SEM in the developed research model. The structural paths were estimated to examine the hypothesized relationships among independent and dependent variables, graphically displayed in Figure 1. The observed variables are enclosed in squares, and the latent variables are enclosed in circles. A one-way path between constructs is indicative of a hypothesized direct effect of one construct on another.

Table 2. Pearson Correlation, Means, Standard Deviations, And Cronbach Alpha Reliability Among Model Variables

\begin{tabular}{ccccccc}
\hline & SE & SEA & ROE & UOE & OEA & Cronbach's Alpha \\
\hline SE & 1.000 & $.481 * * *$ & $.536 * * *$ & $.474 * * *$ & $.558 * * *$ & 0.911 \\
SEA & & 1.000 & $.432 * * *$ & $.333 * * *$ & $.403 * * *$ & 0.868 \\
ROE & & & 1.000 & $.397 * * *$ & $.464 * * *$ & 0.818 \\
UOE & & & 1.000 & $.351 * * *$ & 0.880 \\
OEA & & & & 1.000 & 0.904 \\
Mean & 3.985 & 4.179 & 3.890 & 4.143 & 3.991 & \\
SD & 0.496 & 0.509 & 0.609 & 0.744 & 0.570 & \\
\hline
\end{tabular}

Note: SEA, Self-Emotion Appraisal; ROE, Regulation of Emotion; UOE, Use of Emotion; OEA, Others' Emotion Appraisal; SE, Self-efficacy $* p<.05, * * p<.01, * * * p<.001$

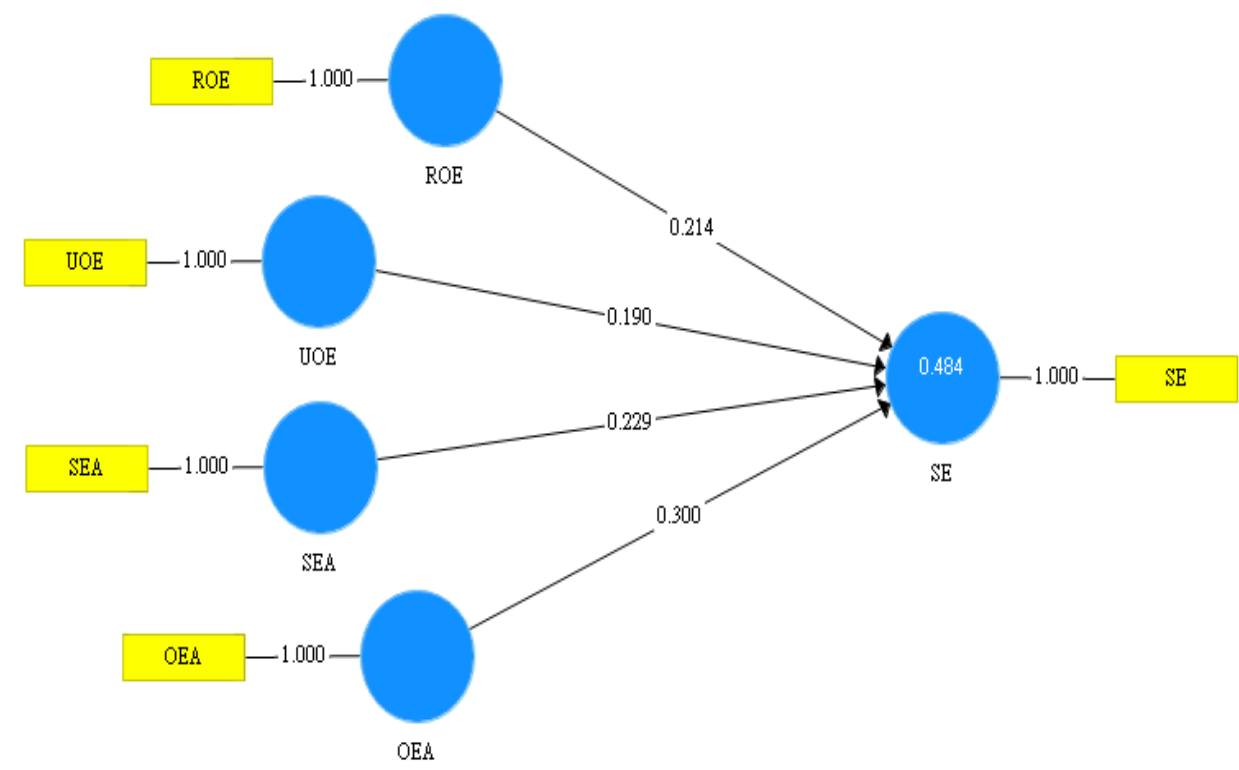

Figure 1 Results of Structural Equation Model 


\author{
E-ISSN: 2469-6501 \\ VOL: 7, ISSUE: 12 \\ December/2021 \\ DOI: http://dx.doi.org/10.33642/ijbass.v7n12p2 \\ (c) (†) \\ https://creativecommons.org/licenses/by/4.0/
}

Within the overall model, the estimates of the The findings fully supported the hypotheses, and these findings structural coefficients provide the basis for testing the are consistent with the results in previous studies. In addition, proposed hypotheses. Table 3 reports the results of the the total effect is therefore recognized based on the structural hypothesis tests, and all paths in the model were significant. coefficients.

Table 3. Summary of Hypothesis Testing Results

\begin{tabular}{ccccc}
\hline Path & Structural coefficients & SE & t-Value & Test result \\
\hline $\mathrm{ROE} \rightarrow \mathrm{SE}$ & 0.214 & 0.055 & $3.485^{* *}$ & Support \\
$\mathrm{UOE} \rightarrow \mathrm{SE}$ & 0.190 & 0.057 & $4.051 * * *$ & Support \\
$\mathrm{SEA} \rightarrow \mathrm{SE}$ & 0.229 & 0.087 & $2.460^{*}$ & Support \\
$\mathrm{OEA} \rightarrow \mathrm{SE}$ & 0.300 & 0.052 & $5.740^{* * *}$ & Support \\
\hline
\end{tabular}

$$
* \mathrm{p}<.05, * * \mathrm{p}<.01, * * * \mathrm{p}<.001
$$

\section{CONCLUSION}

Self-efficacy refers to people's beliefs about their ability to perform certain behaviors or deal with environmental demands. As such, it can be seen as the chief construct linking ability to performance. The purpose of the study is to explore the relationships of self-efficacy on four dimensions of EI, including Self-Emotion Appraisal (SEA), ROE, Regulation of Emotion (ROE), Use of Emotion (UOE), and Others' Emotion Appraisal (OEA). The obtained results indicated that selfefficacy and four dimensions of EI were positively correlated; tour guides with higher EI levels reported having more selfefficacy. The results are consistent with previous research showing these relationships for other settings.
Tour guides play an important role in the tourism industry, as they significantly influence tourists' perception of the host destination. Consequently, it is important to devise a strategy for increasing tour guides' competencies of EI because EI abilities can be learned through proper EI training interventions. If so, tour guides can benefit from EI interventions and self-efficacy abilities can be improved, which allows individuals to become more confident in dealing with challenging situations.

\section{ACKNOWLEDGMENT}

This research was funded by a research grant from the Ministry of Science and Technology in Taiwan (MOST 1072410-H-130 -032 -MY2).

\title{
REFERENCES
}

Bandura, A. (1977). Self-efficacy: Toward a unifying theory of behavioral change. Psychological Review, 84(2), 191-215.

Bandura, A. (1997). Self-efficacy in changing societies. New York: Cambridge University Press.

Bar-On, R. (1997). The emotional quotient inventory (EQ-i): Technical Manual. Toronto: Multi-Health Systems.

Bedwell, S. (2002). Emotional judgment inventory: Research manual. Champaign, IL: Institute for Personality and Ability Testing.

Chan, D.W. (2004). Perceived emotional intelligence and self-efficacy among Chinese secondary school teachers in Hong Kong," Personality and Individual Differences. 36(8), 1781-1795.

Dixon, F., Yssel, N., McConnell, J., \& Hardin, T. (2014). Differentiated instruction, professional development, and teacher efficacy. Journal for the Education of the Gifted, 37(2), 111-127.

Goleman, D. (1995). Emotional intelligence: Why it can matter more than IQ. New York: Bantam Books.

Goleman, D. (1998). Working with emotional intelligence. Bantam Books: New York.

Idrus, S., Alhabji, T., Al Musadieq, M., \& Utami, H. (2015). The effect of psychological empowerment on self-efficacy, burnout, emotional intelligence, job satisfaction, and individual performance. European Journal of Business and Management, 7(8), 139-148.

Jiang, Z. (2014). Emotional intelligence and career decision-making self-efficacy: National and gender differences. Journal of Employment counseling, 51(3), 112-124.

Kraut, R., Chandler, T., \& Hertenstein, K. (2016). The interplay of teacher training, access to resources, years of experience and professional development in tertiary ESL reading teacher' perceived self-efficacy. Gist Education and Learning Research Journal, 12, 132-151.

Mayer, J.D., \& Geher, G. (1996). Emotional intelligence and the identification of emotion. Intelligence, 22, 89-113. 
Mayer, J.D., \& Salovey, P. (1993). The intelligence of emotional intelligence. Intelligence, 17, 433- 442.

Mayer, J.D., \& Salovey, P. (1997). What is emotional intelligence? In P. Salovey \& D. Sluyter (Eds), Emotional development, emotional literacy, and emotional intelligence, (pp 3-31). Basic Books: New York.

Min, J. (2014). The relationships between emotional intelligence, job stress, and quality of life among tour guides. Asia Pacific Journal of Tourism Research, 19(10), 1170-1190.

Salovey, P., \& Mayer, J.D. (1990). Emotional intelligence. Imagination, Cognition, and Personality, 9(3), 185-211.

Schwarzer, R., \& Jerusalem, M. (1995). Generalized Self-Efficacy scale. In J. Weinman, S. Wright, \& M. Johnston, Measures in health psychology: A user's portfolio, Causal and control beliefs (pp. 35-37). Windsor, UK: NFER-NELSON.

Tabatabaei, S., Jashani, N., Mataji, M., \& Afsar, N.A. (2013). Enhancing staff health and job performance through emotional intelligence and self-efficacy. Procedia - Social and Behavioral Sciences, 84, 1666-1672.

Tourism Bureau (2018). Tour guides' statistics. http://admin.taiwan.net.tw/statistics/month.aspx?no=135

Walter, O., Shenaar-Golan, V., \& Greenberg, Z. (2015). Effect of short-term intervention program on academic self-efficacy in higher education. Psychology, 69(10), 1199-1215.

Wong, C.S., \& Law, K.S. (2002). The effects of leader and follower emotional intelligence on performance and attitude: An exploratory study. The Leadership Quarterly, 13(3), 243-274. 